\title{
REINSERÇÃO ESCOLAR NA ÓTICA DO EDUCANDO QUE ESTEVE EM
}

\author{
ATENDIMENTO ESCOLAR DOMICILIAR
}

\section{SCHOOL REINTEGRATION IN THE LEARNER WAS ATTENDING HOME SCHOOL}

\author{
Monique Gonçalves Amâncio ${ }^{1}$ \\ Everson Ney Huttner Castro ${ }^{2}$
}

\begin{abstract}
RESUMO: O objetivo do presente estudo é analisar na ótica do aluno as percepções a cerca da reinserção escolar após o atendimento escolar domiciliar. Participaram do estudo três crianças em tratamento oncológicos, com idades variando entre sete e quatorze anos, residentes em municípios que abrangem a grande Criciúma. A presente pesquisa possui característica descritiva, com abordagem qualitativa. O referencial teórico foi fundamentado nas ideias e experiências de Paterlini (2008), Fonseca (2003), Cardoso et al (2007), entre outros. Foi utilizado como técnica de coletas de dados a entrevista semiestruturada. Os resultados indicaram que os participantes percebem a reinserção escolar como um espaço que promove o bem-estar e a motivação, é bastante evidente nas falas das crianças o quanto elas sentem falta da escola regular, da convivência com os colegas, das atividades recreativas, da presença diária de um professor, ou seja, há uma valorização do espaço escolar de maneira positiva. A partir disso, compreende-se que há necessidade de desenvolver um trabalho interdisciplinar que possibilite desenvolver estratégias que potencializem as habilidades do sujeito e a sua readaptação ao contexto escolar.
\end{abstract}

PALAVRAS CHAVE: Inclusão; Exercício domiciliar; Interações sociais; Aprendizagem.

ABSTRACT The objective of the present study is to assess the student's optical perceptions about school reintegration after school care at home. Participated in this study three children in cancer treatment, with ages ranging between seven and fourteen years, residents in municipalities covering huge Criciúma. The present research has descriptive feature, with a qualitative approach. The theoretical framework was based on the ideas and experiences of Paterlini (2008), Francis (2003), Cardoso et al. (2007), among others. Was used as the data collection technique the semi-structured interview. The results indicated that participants perceive the school reintegration as a space that promotes the well-being and motivation, it is

\footnotetext{
${ }^{1}$ Monique Gonçalves Amâncio graduanda do Curso de Pedagogia da Universidade do Extremo Sul Catarinense UNESC. E-mail: nick_g.a@ hotmail.com

${ }^{2}$ Everson Ney Huttner Castro professor do Curso de Pedagogia da Universidade do Extremo Sul Catarinense UNESC. Pedagogo e Especialista em Educação - Orientação Educacional. E-mail: everson.castro@hotmail.com Saberes Pedagógicos, Criciúma, v. 2, nº1, janeiro/junho 2018.- Curso de Pedagogia- UNESC
} 


\section{SABERES PEDAGÓGICOS}

Revista do Curso de Graduaçāo de Pedagogia - Unesc

ISSN $2526-4559$

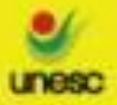

Thisming

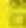

quite evident in the lines of the children how much they miss their regular school, shared with colleagues, recreational activities, the daily presence of a teacher, that is, there is an appreciation of school space positively. From this, it is understandable that there is a need to develop an interdisciplinary work that makes it possible to develop strategies to strengthen the abilities of the subject and your upgrading to the school context.

KEYWORDS: Inclusion; Home exercise; Social interactions; Learning.

\section{INTRODUÇÃO}

O presente tema surgiu a partir da minha experiência de trabalho na área da saúde, onde atuei por seis anos, como técnica de enfermagem. No decorrer dessa trajetória lidei com crianças oncológicas, surgindo assim, o interesse em compreender o dia a dia das mesmas no contexto escolar.

Partindo da premissa que as crianças em tratamento prolongado decorrente de alguma doença passam dias internadas no hospital, sabe-se que ela não frequenta a escola regular, deixando de desenvolver as atividades escolares. Sendo assim, pressupõe-se que estão sujeitos a apresentar alguma dificuldade de aprendizagem, o que nos levou a formular o seguinte problema: quais as expectativas da criança que esteve em exercício domiciliar de retorno para sala de aula?

A investigação que se propôs, em nível de pesquisa no curso de licenciatura em Pedagogia da UNESC, é inovadora, uma vez que não há estudo realizado nessa área em nível de conclusão de curso, o que me motivou para o desenvolvimento deste trabalho, uma vez que poderá tornar-se um novo campo de estudo para futuros pedagogos.

Para o desenvolvimento da temática proposta, esta pesquisa teve como objetivo geral analisar, na perspectiva da criança que esteve em exercício domiciliar, suas expectativas de retorno para sala de aula. O objetivo geral foi orientado pelos seguintes objetivos específicos: definir atendimento escolar domiciliar; verificar como a literatura afirma que deva ocorrer o atendimento escolar domiciliar; de acordo com a literatura, o que a escola deve fazer para facilitar a inclusão de crianças que estiveram em exercício domiciliar; identificar crianças que estiveram em atendimento escolar domiciliar; levantar quais as expectativas de retorno para a escola da criança que esteve em atendimento escolar domiciliar; questionar se a

Saberes Pedagógicos, Criciúma, v. 2, nº1, janeiro/junho 2018.- Curso de Pedagogia- UNESC 

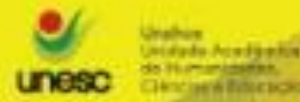

unese

edineso

criança teve suas expectativas respondidas ao retornar do atendimento escolar domiciliar. Para que esses objetivos fossem atingidos utilizou-se como procedimento metodológico a entrevista semiestruturada de caráter exploratório.

A linha de pesquisa ligada a este estudo é a de Teoria e Prática Pedagógica, cujo eixo temático é o processo de ensino - aprendizagem, onde discute as relações na escola e ambientes equivalentes, enfatizando as diferentes concepções e implicações no processo de ensino - aprendizagem como suporte para a prática pedagógica.

\section{EXERCÍCIO DOMICILIAR: O DIREITO A EDUCAÇÃO}

De acordo com o Decreto-lei $\mathrm{n}^{\circ} 1.044$, de 21 de outubro de 1969, o aluno que estiver incapacitado de frequentar as aulas regulares terá o direito ao exercício domiciliar a fim de garantir o seu direito de acesso e permanência na escola (Brasil, 1996). Mesmo que o aluno se encontra em condições de aprendizagem, nem sempre a sua condição de saúde permite sua frequência escolar imposta em lei, sendo que

Art. $1^{\circ}$ - A educação abrange os processos formativos que se desenvolvem na vida familiar, na convivência humana, no trabalho, nas instituições de ensino e pesquisa, nos movimentos sociais e organizações da sociedade civil e nas manifestações culturais. (BRASIL,1996).

Portanto o aluno portador de alguma limitação que impossibilita temporariamente a sua presença em sala de aula, tais como; infecções, traumatismo, câncer ou qualquer incapacidade física tem o direito a ser atendido no leito hospitalar ou em seu domicílio.

Ainda com base no Decreto-lei $\mathrm{n}^{\circ} 1.044 /$ de 1969, para que o aluno possa ter direito ao atendimento domiciliar, o mesmo terá que apresentar um laudo médico assinado por uma autoridade, sendo este pedido feito pelo diretor da escola em que o aluno encontrasse matriculado. Entretanto, se o diretor entender que o tempo de afastamento seja prolongado demais, prejudicando e comprometendo o aprendizado, o pedido de exercício domiciliar poderá ser recusado pela escola.

Cardoso et al (2007, p.11) afirma que "o processo de hospitalização, tanto para criança quanto para o adolescente é muito marcante", a doença passa a ser algo real para ela, ocasionando grandes marcas em seu corpo e mente, isso acontece com mais força durante a

Saberes Pedagógicos, Criciúma, v. 2, nº1, janeiro/junho 2018.- Curso de Pedagogia- UNESC 


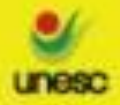

adolescência, pois seu corpo físico passa por modificações devido a agressividade do tratamento.

Essas alterações no corpo físico podem provocar o afastamento dessas crianças do ambiente escolar, especialmente no período mais instável do tratamento, na qual o educando poderá submeter-se a cirurgias, longos tratamentos ou sessões de quimioterapia e radioterapia. No que lhe concerne, os pais buscam proteger seus filhos que se encontram em circunstância de vulnerabilidade, como esforços físicos, intelectual ou social e, consequentemente, podem acabar impedindo a criança de frequentar a escola (CARDOSO et al, 2007).

Cohen e Melo (2010), afirmam que é visível o quanto os professores e diretores, assim como todos os envolvidos com a escola, sentem com a ausência de informações de como agir com esse aluno que por tal motivo esteve afastado da sala de aula. Existe uma privação sobre esse assunto, é necessário um diálogo entre educadores, profissionais da saúde e familiares, a fim de tornar possível a integridade desse aluno com aquilo que é de direito seu, o direito a uma educação com qualidade.

Paterlini e Boemer (2008) enfatizam que "a comunicação afetiva com esses profissionais sobre o diagnóstico e tratamento do estudante, contribui de maneira determinante para o retorno do aluno a sala de aula".

Esses são alguns dos fatores que afetarão no desenvolvimento escolar da criança com algum diagnóstico de problema de saúde, pois agregando ao receio existem restrições como dor, mal-estar e dificuldades emocionais, que podem tornar-se obstáculos para a sua volta à sala de aula.

\section{INCLUSÃO E GARANTIA DE IGUALDADE E PERMANÊNCIA DOS EDUCADOS}

O Estatuto da Criança e do Adolescente, em seu Art. 53 garante a igualdade de acesso e permanência dos estudantes na escola a, para que isso ocorra as Diretrizes Nacionais para a Educação Especial na Educação Básica, instituída pelo Conselho Nacional de Educação (CNE) com a Resolução $n^{\circ}$ 2/2001, afirma que é imprescindível que todas as crianças e adolescentes sejam atendidos pela escola independente de seu estado de saúde ou desenvolvimento e orienta a organização do atendimento educacional especializado a alunos impossibilitados de frequentar as aulas devido a tratamento de saúde que implique internação

Saberes Pedagógicos, Criciúma, v. 2, nº1, janeiro/junho 2018.- Curso de Pedagogia- UNESC 

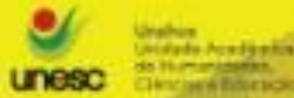

unese

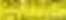

hospitalar, atendimento ambulatorial ou permanência prolongada em domicílio. As classes hospitalares e o atendimento em ambiente domiciliar devem dar continuidade ao processo de desenvolvimento e de aprendizagem de alunos matriculados em escolas da Educação Básica, contribuindo para o seu retorno e reintegração ao grupo escolar.

A política de educação especial de Santa Catarina, em conformidade com a Resolução $n^{\circ}$ 2/2001/CNE/CEB, garante ao aluno portador de alguma necessidade especial de aprendizagem em idade escolar de zero a dezessete anos sua matricula e frequência nas escolas de educação básica, e, para assegurar essa permanência com qualidade, é dever do poder público disponibilizar recursos e serviços de educação especial, a fim de garantir o prosseguimento em seu processo educacional. (BRASIL, 2001).

Este aspecto também é mencionado na Lei de Diretrizes e Bases da Educação Nacional de 1996, especificamente no capítulo $\mathrm{V}$ do documento, firma que o aluno, necessitado de atendimento excepcional em virtude de alguma incapacidade, seja ela mental ou física, receberá apoio educacional especializado com professores com especialização adequada para estar possibilitando a integração desses alunos as classes comuns, bem como; recursos educativos, técnicas, métodos e currículos. Isto porque

Art. 22: A educação básica tem por finalidades desenvolver o educando, assegurarlhe a formação comum indispensável para o exercício da cidadania e fornecer-lhe meios para progredir no trabalho e em estudos posteriores (BRASIL 1996).

Importa ainda salientar que é de grande importância que a comunidade escolar, junto com os pais ou responsáveis, zelem pela integração entre aluno e escola, proporcionando assim o interesse da criança em não desistir de sua vida escolar, enfatizando o valor de sua carreira acadêmica.

A despeito disso, Paterlini e Boemer (2008) afirmam que a conservação das atividades cotidianas assim como a frequência escolar da criança acamada contribui para que ela cultive a esperança de sobreviver, perante a construção de seu futuro.

Ao referir-se a tal assunto, Pinto (2012) diz que é inegável a importância da relação da família com a escola no que refere na formação acadêmica e social da criança, pois quando se trona inviável a sua frequência em sala de aula durante o tratamento, a criança necessita continuar a desenvolver habilidades cognitivas e sociais, além da formação da

Saberes Pedagógicos, Criciúma, v. 2, nº1, janeiro/junho 2018.- Curso de Pedagogia- UNESC 

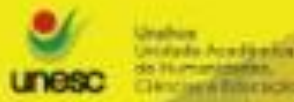

unese

própria autonomia, competências e ética, e, principalmente, a adquirir conhecimentos acadêmicos.

A criança que fica afastada da escola por um período, antes mesmo de ela retornar ao seu antigo grupo, ela tem em mente que algo será diferente, pois houve muitas mudanças enquanto esteve longe, conteúdos novos foram aprendidos, vivencias novas entre os amigos aconteceram, e, por algum motivo, ela não estava presente. Em face disso, é necessário que a turma e a escola que essa criança frequentava possam saber identificar em sua volta quais os anseios que ela enfrenta e as suas expectativas em estar voltando a sua antiga rotina.

É fundamental que todas as escolas sejam capazes de suprir essas necessidades que, por algum motivo de saúde, esse aluno esteve impossibilitado de estar presente em sala de aula. É dever da escola garantir o acesso e permanência do estudante em sala de aula. A escola, então, deve dar suporte por meio do exercício domiciliar e estar identificando alguns pontos fundamentais para que isso se torne possível, como; situar teoricamente o exercício domiciliar como direito de todos, identificar as crianças que estiveram em exercício domiciliar, perceber as expectativas delas ao retornar para a sala de aula, estar apontando questões de melhoria facilitando o reingresso dessas crianças, estar constatando se houve prejuízo no seu processo educacional e compreender os medos que elas enfrentam em função das mudanças em sua vida escolar e social.

\subsection{A Pedagogia na área hospitalar}

Esteves (2008) afirma que a classe hospitalar tem seu início em 1935, quando Henri Sellier inaugura a primeira escola para crianças inadaptadas, nos arredores de Paris. Sua ação repercutiu na Alemanha, França, Europa e nos Estados Unidos, com o intuito de suprir as dificuldades escolares de crianças tuberculosas. Um dos marcos decisório para as escolas em hospitais foi a Segunda Guerra Mundial, pois o grande número de crianças e adolescentes mutilados e impossibilitados de ir à escola, fez surgir a necessidade deste serviço.

Segundo Gomes e Rubio (2012), no Brasil o exercício de um professor nas classes hospitalares é de proporcionar a continuidade ao desenvolvimento do ensino e aprendizagem das crianças e adolescentes que se encontram hospitalizados, sempre dando ênfase ao estado emocional do sujeito. Entretanto, o campo de atuação da pedagogia hospitalar ainda é 


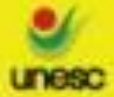

pequeno, pois se refere de uma área pouco explorada e com vago conhecimento sobre a essa classe.

\begin{abstract}
O ambiente hospitalar é um centro de referência e tratamento de saúde, que acaba por gerar um ambiente muitas vezes de dor, sofrimento e morte, causando uma forma de ruptura dessas crianças e adolescentes com os laços que mantém com seu cotidiano e produção da existência da construção de sua própria aprendizagem (GOMES; RUBIO, 2012 p. 2)
\end{abstract}

O pedagogo tem papel fundamental no ambiente hospitalar, pois fará o elo da criança enferma com seu desenvolvimento escolar, o educador tem como função dar continuidade ao processo educacional dessa criança hospitalizada.

Os referidos autores consideram que a pedagogia atua na área da construção do conhecimento, ou seja, o profissional desse campo é o mais apto para estar trabalhando com esses alunos. O professor que se faz presente nesse meio será o mediador entre hospital e escola, preservando o bem-estar do educando.

Outro aspecto levantado por Gomes e Rubio (2008), é os efeitos que esse trabalho pedagógico trás para a criança enferma, entendem que a presença do pedagogo no ambiente hospitalar tem como objetivo recuperar a socialização da criança por meio de um processo de inclusão, dando segmento ao seu processo de aprendizagem, isto é, acolher pedagogicamente as necessidades cognitivas e proporcionando experiências sócio intelectivas do seu grupo social escolar.

\title{
3.2 O professor e a escola no atendimento pedagógico hospitalar ou domiciliar
}

O professor que irá atuar em classe hospitalar ou no atendimento pedagógico domiciliar, m seu primeiro contato com o estudante, se possível, deve contar com a presença da mãe ou do pai, pois a mesma encontra-se em um momento frágil de sua vida e a presença de alguém que não seja de sua família pode trazer certo desconforto a ela, promovendo assim a melhor forma de estabelecer a interação com a criança enferma. (FONSECA, 2003)

Vale destacar que,

Saberes Pedagógicos, Criciúma, v. 2, nº1, janeiro/junho 2018.- Curso de Pedagogia- UNESC 


\section{SABERES PEDAGÓGICOS}

Revista do Curso de Graduaçāo de Pedagogia - Unesc

ISSN 2526-4559

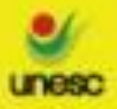

Thisuing

matrons

Para atuar em classe hospitalar o professor deverá estar habilitado para trabalhar com diversidade humana e diferentes experiências culturais, identificando as necessidades educacionais especiais dos educandos impedidos de frequentar a escola, decidindo e inserindo modificações e adaptações curriculares em um processo flexibilizador de ensino/aprendizagem (GOMES; RUBIO, 2012 p. 2).

Segundo Avanzini e Silva (2011), o professor atuante em classe hospitalar ou domiciliar, de forma alguma deve perder o foco da sua atuação, que é ser o vínculo do conhecimento, a postura do educador é de fornecer a aproximação desse aluno impossibilitado ao saber escolar, contribuindo para o retorno e a reintegração ao grupo escolar.

Cardoso et all (2007) relata que o professor que atuar na área da pedagogia hospitalar ou domiciliar deverá ter formação pedagógica em educação especial ou em cursos de pedagogia ou licenciaturas. Afirmam ainda que é de suma importância o professor ter conhecimento sobre as doenças e condições psicossociais as suas características decorrentes vivenciadas pelos os educandos, sejam elas do ponto de vista clinico ou afetivo. É de competência do professor domiciliar adequar e adaptar o ambiente às atividades e aos materiais, planejar o dia-a-dia, registrar e avaliar o trabalho pedagógico desenvolvido (BRASIL, 2002)

Outro aspecto levantado é a reintegração do educando que ficou temporariamente impedido de frequentar a escola por motivo de saúde, cabe a escola ter atenção voltada para alguns aspectos para garantir da melhor forma a volta desse estudante para o seu grupo escolar como o desenvolvimento da acessibilidade e da adaptabilidade; a manutenção do vínculo com a escola durante o período de afastamento, por meio da participação em espaços específicos de convivência escolar previamente planejados; momentos de contato com a escola por meio da visita dos professores ou colegas do grupo escolar correspondente e dos serviços escolares de apoio pedagógico (sempre que houver a impossibilidade de locomoção mesmo que esporádica); garantia e promoção de espaços para acolhimento, escuta e interlocução com os familiares do educando durante o período de afastamento; preparação ou sensibilização dos professores, funcionários e demais alunos para o retorno do educando com vistas à convivência escolar gradativa aos espaços de estudos sistematizados. (BRASIL, 2002).

Sabe-se que a escola realiza um papel muito importante para a construção da vida social e profissional de um individuo, perante isso a reinserção escolar da criança que esteve

Saberes Pedagógicos, Criciúma, v. 2, nº1, janeiro/junho 2018.- Curso de Pedagogia- UNESC 

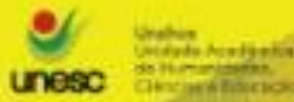

unesc

afastada da escola é um momento de aprendizagem, acolhimento, e também um resgate da sua rotina anterior ao fato que lhe fez estar se ausentando da escola.

Nesse mesmo ponto de vista, voltado com olhar para a escola, Brasil (2002) afirma que o espaço escolar que o aluno já frequentava deve levar em consideração alguns aspectos importantes que afetam a reinserção do aluno a sua antiga escola, como desenvolver projetos de acessibilidade e adaptabilidade, manter o vínculo da escola com o aluno no período de afastamento, promovendo momentos de contato com a escola por meio de visitas dos professores e colegas, garantindo um espaço de acolhimento que seja confortável tanto para o aluno quanto para os familiares, cabendo, também, a preparação dos professores, funcionários e colegas com o intuito de garantir melhor o retorno e a convivência escolar desse aluno afastado.

O documento também realça a importância do trabalho multiprofissional entre educação e saúde, possibilitando de forma integral o acolhimento pedagógico do aluno; o atendimento pedagógico deverá ser orientado pelo processo de desenvolvimento e construção do conhecimento correspondente à educação básica, exercido numa ação integrada com os serviços de saúde (BRASIL, 2002)

Desta forma é possível ofertar com melhor eficiência a prática didáticopedagógica, promovendo a saúde e bem-estar da criança e ofertando um melhor retorno aos estudos para esses educandos.

\section{METODOLOGIA, APRESENTAÇÃO E ANÁLISE DE DADOS}

Sendo o principal objetivo deste estudo a análise das expectativas em relação ao retorno ao ambiente escolar da criança que esteve em atendimento escolar domiciliar por tratamento de saúde, optou-se por uma metodologia de natureza aplicada de aspecto qualitativo.

As pesquisas que se utilizam de abordagem qualitativa possuem a facilidade de poder descrever a complexidade de uma determinada hipótese ou problema, analisar a interação de certas variáveis, compreender e analisar processos dinâmicos experimentados por grupos sociais, apresentar contribuições no processo de 
mudança, criação ou formação de opiniões de determinado grupo.[...] (OLIVEIRA, 1999, p.117).

De acordo com Gil (1991), para realizar uma pesquisa com qualidade é necessário ter o conhecimento do assunto a ser pesquisado, ser criativo, curioso e ter integridade intelectual e sensibilidade social.

Tendo em vista os objetivos previstos o estudo foi do tipo exploratório, pois envolve uma primeira aproximação com pessoas que enfrentaram problemas referente ao assunto pesquisado. "Estas pesquisas tem como objetivo proporcionar maior familiaridade com o problema, com vistas a torná-lo mais explícito ou a construir hipóteses." (GIL, 1991, p.41)

O instrumento utilizado para a coleta de dados foi a entrevista semi-estruturada, uma vez que guarda a possibilidade do entrevistador acrescenta perguntas quando não compreender claramente as respostas apresentadas pelo investigado. Para cada envolvido na coleta de dados foi encaminhado o termo de consentimento escrito para ser assinado pelo responsável legal do educando. Por uma questão ética foi garantido o absoluto resguardo de sigilo dos entrevistados que serão referenciados como E1, E2 e E3.

A entrevista contou com um roteiro com dez perguntas elaboradas previamente a fim de elucidar os objetivos propostos. A entrevista foi aplicada a três indivíduos com idade de 7 (sete) a 14 (catorze) anos, que residem na região da grande Criciúma/SC e que estiveram afastados da escola por um determinado período para tratamento médico, motivo pelo qual foram acompanhados por professor designado pela escola para dar acompanhamento pedagógico enquanto não podiam frequentar a escola regular. Importa, ainda, salientar, que os três investigados já haviam retornado para o ambiente escolar. Os três educandos que cumpriam os requisitos necessários para esta investigação foram indicados através de contato com uma enfermeira do setor de oncopediatria de uma unidade hospitalar da cidade de Criciúma, ou seja, não foi estabelecida amostra, pois foram envolvidos a totalidade dos sujeitos que respondiam ao perfil necessário a esta investigação. Após entramos em contato com os responsáveis legais desses três alunos para que os mesmos autorizassem por meio de termo de consentimento assinado a participação dos referidos educandos nesta pesquisa. 
Por uma questão de ética, não serão identificados os sujeitos investigados, mantendo-se o sigilo a respeito dos mesmos. Para tal, serão identificados como $E^{1}, E^{2}$ e $E^{3}$ ao longo da análise dos dados coletados.

\section{REINSERÇÃo ESCOLAR APÓS AFASTAMENTO POR TRATAMENTO DE SAÚDE: O QUE A ANÁLISE DOS DADOS APONTA}

Perante os conteúdos apresentados nesse trabalho sobre a reinserção escolar da criança em exercício escolar domiciliar, trago agora a descrição e análise dos dados coletados na pesquisa de campo.

Para melhor analisar os dados coletados, realizou-se a organização dos mesmos em três categorias de análise: identificação dos entrevistados; expectativas ao retornar para a escola; a realidade escolar para a reinserção do educando.

\subsection{Identificação dos entrevistados}

No inicio da conversa com os entrevistados questionou-se suas identificações e o período de afastamento da escola e o motivo.

$\mathrm{E}^{1}$ : a entrevista se realizou em sua própria residência com a autorização e a presença dos pais o entrevistado possui 11 anos de idade é estudante do sexto ano do Ensino Fundamental II, ficou afastado por 1 ano e 6 meses do ambiente escolar, pois descobriu com 9 anos que tinha um tumor na cabeça.

E2: a entrevista também se realizou nas dependências de sua casa com a autorização e a presença da mãe que também é pedagoga, a criança possui 7 anos de idade, é portadora da leucemia do tipo LLA( linfoide aguda), estudante do primeiro ano do Ensino Fundamental I, ficou afastada da escola por 1 ano e 5 meses para tratamento com quimioterapia.

$E^{3}$ : 14 anos de idade, a entrevista foi realizada em minha residência, com a presença e autorização da mãe, pois o aluno mora um pouco afastado de criciúma, e na semana que entrei em contato o mesmo viria para a cidade em sua consulta médica. É 

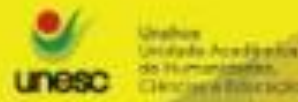

estudante do oitavo ano do Ensino Fundamental II e ficou afastado da escola no período de 1 ano e 5 meses, para também se tratar da leucemia.

\subsection{Expectativas ao retornar para a sala de aula}

Sobre as expectativas dos alunos entrevistados em relação ao seu retorno para a sala de aula, percebeu-se que o medo e a insegurança de como seriam vistos sobre os olhares de seus colegas e suas professoras eram baste visível em suas falas. Segundo Cardoso et al (2007) o processo de hospitalização, tanto para criança quanto para o adolescente é muito marcante. Diante de tantas transformações repentinas, tanto física e psicológica, é esperado que a criança atravesse períodos de questionamentos sobre sua volta para a escola.

Diante desse pressuposto o $\mathrm{E}^{1}$ encontra-se matriculado no ensino fundamental de uma escola na cidade de Nova Veneza, localizada no Estado de Santa Catarina. Ao responder as perguntas sobre suas expectativas em retornar para a sala de aula, declarou que em primeiro momento achou que seus colegas iam rir dela, pois como passou por seções de radioterapia e quimioterapias, acabou perdendo seus cabelos, ficando assim com sua aparência diferente, mais que não via a hora de estar junto deles. Entretanto a mesma disse que se surpreendeu no seu primeiro dia de aula, já que todos seus amigos a receberam muito bem, e não a trataram com diferença. $\mathrm{E}$ as professoras a tratava com muita paciência, pois sabiam que por ter passado por longos dias em tratamento com quimioterapia e radioterapia era normal ela possuir algum tipo de dificuldade no aprendizado.

No mesmo pensamento o $\mathrm{E}^{2}$ relata que seu maior receio ao retornar para a escola era com seus amigos, já que com as professoras possuía um vinculo por estarem sempre perguntando sobre seu estado de saúde, em que sua mãe também é professora, mas com seus colegas sentia que talvez iria ter um pouco de dificuldade para lidar com toda essa transformação, dado que quando voltou para a escola ainda estava fazendo algumas seções de quimioterapia, perante isso ainda fazia uso do cateter port a catt ${ }^{3}$, entretanto o que seria algo estranho para seus colegas, acabou virando o motivo de aproximação, a $E^{2}$ relata que seus

\footnotetext{
${ }^{3}$ cateter port-a-cath é um dispositivo que fica acoplado abaixo da pele e consiste em um reservatório com membrana perfurável e um cateter de silicone, ele pode ser utilizado para infusão de sangue (transfusões), coleta de sangue, antibióticos, analgésicos, nutrição parenteral e principalmente para infusão de quimioterapia.

Saberes Pedagógicos, Criciúma, v. 2, nº 1, janeiro/junho 2018.- Curso de Pedagogia- UNESC
} 
amigos a ajudava muito, estavam sempre em sua volta, querendo cuidar dela, e principalmente com o port a catt, que elas o chamavam de "maquininha". Com o conteúdo escolar, sentia as vezes dificuldade, mais as professoras sempre a ajudava muito. A mesma atualmente é matriculada na escola do ensino fundamental da cidade de Cocal do Sul.

$\mathrm{O} \mathrm{E}^{3}$ é aluno do ensino fundamental da cidade de Arroio do Silva, localizada no mesmo Estado, e, por se tratar de um pré-adolescente, é muito visível em sua fala a preocupação em relação aos seus amigos, o medo de ter que enfrentar o preconceito, e como lidar com ele. Relatou que por conta da quimioterapia não conseguia se alimentar, e foi obrigado a fazer uso de uma sonda nasogástrica, que, para ele, foi um dos piores momentos o tratamento, pois sentia muita vergonha. Nesse período, $\mathrm{E}^{3}$ já estava liberado para frequentar as aulas, porem não ia para não passar vergonha. Após um período com a sonda ele pode tirá-la, e quando voltou para a escola percebeu que todos seus amigos mais próximos haviam se mudado, ficando apenas um, por se considerar muito tímido e fechado, teve um pouco de dificuldades para fazer novas amizades, mais não por causa da doença e sim pelo seu jeito.

Em relação às expectativas em relação ao retorno para a sala de aula fica evidente a preocupação dos estudantes em como seria a sua acolhida na escola, uma vez que estariam a se sentir diferentes dos demais. Importa, ainda, destacar que, além dos educandos se apresentaram preocupados com o reencontro dos colegas de classe e como esses reagiriam no processo de acolhida, a preocupação com a aprendizagem dos conteúdos desenvolvidos em sala de aula e as condições que teriam para acompanhar os trabalhos desenvolvidos junto ao grupo de estudantes da escola regular.

\subsection{A realidade escolar para a reinserção do educando}

Em relação a possibilidade escolar para a reinserção do educando, é perceptível o quanto é importante que a escola se faça presente nesse momento da vida do aluno, pois é da rotina de toda criança o compromisso com a frequência escolar, e de uma hora para outra isso desaparece fazendo com que o aluno se sinta "perdido" em seu próprio "mundo". Indo ao encontro com o que Cardoso et al, (2007) destaca, de que um fator que causa o afastamento da 

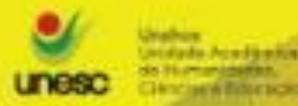

criança da escola relaciona-se a falta de informação do corpo docente, gerando assim atitudes preconceituosas por parte de professores ou de alunos e vice-versa

As respostas dos três entrevistados, foram praticamente muito parecidas, enfatizando a importância do atendimento escolar domiciliar, os três receberam a visita semanal de uma professora em suas residências. Contam que se não fosse a presença dela fazendo esse vínculo entre o aluno e a escola, que era muito valioso, talvez o retorno fosse muito mais traumático, pois além de ter que lidar com os preconceitos perante a doença, teriam ainda que enfrentar a dificuldade de não saber as matérias, o que poderia aumentar o sentimento de exclusão.

Todos os entrevistados apontaram que a escola deveria estar melhorando o retorno dos alunos que ficaram um período afastado das salas de aula para tratamento médico e reforçaram a necessidade da escola etar abordando mais sobre o câncer, dentre outras coisas que gera impedimento do educando, para todos os alunos e não somente para aqueles que por alguma necessidade precisam estar afastados.

Importa acrescentar às sugestões que não somente os alunos se empenham em ajudar, e sim todos que fazem parte da escola, como funcionários, diretores, professores, e ate mesmo a comunidade.

Ainda nessa mesma linha de consideração Brasil (2002,) afirma que o aspecto pedagógico, assim como a readaptação do ambiente escolar, tem um grande peso para reinserção desses alunos, considerando a complexidade do atendimento, tanto domiciliar ou hospitalar, sendo necessário o trabalho em conjunto do sistema de saúde da educação na perspectiva de melhor atendê-los.

Outro aspecto levantando pelo autor é a importância de disponibilizar aos educandos e professores materiais pedagógicos, jogos, vídeos educativos, etc, promovendo melhor o desenvolvimento e construção de novos conhecimentos para essas crianças.

\section{CONCLUSÃO}

O estudo permitiu constatar o quanto é importante dar voz para os educandos que estiveram em atendimento escolar domiciliar. Entende-se que a criança dá muito valor ao seu

Saberes Pedagógicos, Criciúma, v. 2, nº1, janeiro/junho 2018.- Curso de Pedagogia- UNESC 

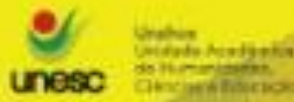

mundo, refletindo nas suas interações sociais. É visível o quanto é importante a integração entre escola e aluno no momento em que este se encontra afastado de sua rotina escolar em decorrência de problemas de saúde.

Essa pesquisa permitiu conhecer e analisar quais as expectativas que esses alunos têm ao retornar para o ambiente escolar após um determinado tempo afastado, assim percebese as atitudes do indivíduo ao se deparar com tal fato. O momento da reinserção escolar é um momento importante na vida do estudante pois envolve reintegração, aprendizado, bem-estar, autoestima, e, assim como a criança que esta retornando, as que recebem também resgatam os relacionamentos sociais.

O presente trabalho pode proporcionar a percepção sobre a importância do momento de retorno do estudante para as atividades escolares, informação essa que deve ser considerada pelos familiares e profissionais envolvidos no acompanhamento desses estudantes durante o tratamento médico e, após, em função do seu retorno para as atividades escolares regulares. Podemos afirmar, então, que o trabalho multiprofissional bem planejado só traz benefícios ao desenvolvimento cognitivo e afetivo desses educandos.

Em virtude da insuficiência de estudos que discutam o tema da reinserção escolar e sua relação com a percepção dos estudantes, sugere-se o desenvolvimento e aprofundamento de novas investigações.

Desse modo, seria relevante, aperfeiçoar os conhecimentos, com base na utilização de outros instrumentos e de um número maior de participantes, assim como, a associação com outras variáveis, a exemplo de atitudes positivas frente à escola e traços de personalidade.

As informações aqui produzidas ficarão à disposição para consulta por meio de publicações que permitam destacar o valor que os educandos atribuem ao processo de reinserção no ambiente escolar regular, já que muitas escolas parecem ainda não dar o devido espaço para a discussão desta temática nos dias de hoje.

\section{REFERÊNCIAS:}




\section{SABERES PEDAGÓGICOS}

Revista do Curso de Graduaçāo de Pedagogia - Unesc

ISSN 2526-4559

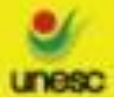

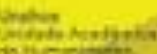

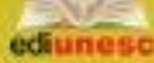

AVANZINI, Claudinéia Maria Vischi; Silva, Thais Gama da. Atendimento Pedagógico Hospitalar e Domiciliar no Município de Araucária e no Estado do Paraná. X ANPED SUL, Florianópolis, outubro de 2014. p. 1-13

BRASIL. Decreto-lei $\mathrm{n}^{\circ} 1.044$ de 21 de outubro de 1969. Institui o exercício domiciliar e dá outras providências. Brasília: DF, 1969.

. RESOLUÇÃO CNE/CEB No 2, DE 11 DE SETEMBRO DE 2001.Institui Diretrizes Nacionais para a Educação Especial na Educação Básica. Brasília: CNE/CEB: 2001.

CARDOSO, Maria Terezinha ET AL. Da classe hospitalar ao espaço escolar. Dosie, Florianópolis, p.1104-1109, abr.2007. Semanal. Disponível em: <http://www.fen.ufg.br/revista/v10/n4/v10n4a28.htm.>. Acesso em: 25 maio. 2017.

COHEN, Ruth Helena Pinto; MELO, Amanda Gonçalves da Silva. Avaliação formativa e formação de professores: ainda um desafio. Linhas críticas, Rio de Janeiro, v.12, p.306325,15 fev.2010. $\quad$. Disponível em: http://periodicos.unb.br/index.php/linhascriticas/article/viewArticle/1684. Acesso em: 28 maio. 2017.

Estatuto da Criança e do Adolescente no Brasil. Lei ${ }^{\circ} 8.069 / 90,13$ de julho de 1990. Disponível em:<http://www.planalto.gov.br/ccivil_03/Leis/L8069.htm>. Acesso em 29 nov. 2016.

ESTEVES, Claudia R. Pedagogia hospitalar: um breve histórico. Publicado em 2008. Disponível em: http://www.santamarina.g12.br/faculdade/revista/artigo4.pdf. Acesso em: 29 maio.2017.

Experiências educacionais inclusivas: Programa Educação Inclusiva: direito à diversidade. Brasília: Ministério da Educação, Secretaria de Educação Especial, 2006.

FONSECA, Eneide Siimões da. Atendimento escolar no ambiente hospitalar. São Paulo: Memnon, 2003. 100p.

GIL, Antônio Carlos. Como elaborar projetos de pesquisa. 3a . ed. São Paulo: Altas. $1991.158 \mathrm{p}$.

GOMES, O. J; RUBIO, S. A. J. Pedagogia Hospitalar: A Relevância da Inserção do Ambiente Escolar na Vida da Criança Hospitalizada. Revista Eletrônica Saberes da Educação. Vol. 3. n 1 - 2012. Disponível em <http://www.facsaoroque.br/novo/publicacoes/pdf/v3-n12012/Janaina.pdf>. 02 abril. 2017.

Ministério da Educação e do Desporto. Secretaria de Educação Fundamental. Lei no. 9.394, de 20 de dezembro de 1996. Estabelece as Diretrizes e Bases da Educação Nacional. Diário Oficial da República Federativa do Brasil, Brasília, DF, Seção 1, p.27834-27841.

Saberes Pedagógicos, Criciúma, v. 2, nº1, janeiro/junho 2018.- Curso de Pedagogia- UNESC 
Disponível em: <https://www.planalto.gov.br/ccivil_03/Leis/L9394.htm>. Acesso em 20 nov. 2016.

OLIVEIRA, Djalma de P.R. Planejamento estratégico: conceitos, metodologias e práticas. 14.ed. São Paulo: Atlas, 1999.

Parecer n. ${ }^{\circ}$ 31/2002 CNE/CEB. Consulta tendo em vista o artigo 24, inciso VI e o artigo 47, § $3^{\circ}$ da LDB. Brasília: CNE/CEB, 2002

PATERLINI, Ana Carolina Carvalho Rocha; BOEMER, Magali Roseira. A reinserção escolar na área de oncologia infantil: avanços \& perspectivas. Revista Eletrônica de Enfermagem, São Paulo, v. 33, p.1152-1158, 10 abr. 2008. Semanal. Disponível em: <http://www.fen.ufg.br/revista/v10/n4/v10n4a28.htm.>. Acesso em: 25 maio 2017.

PINTO, Fábia Patrícia Suzano da Silva. Vida intermitente: A doença oncológica em contexto escolar. Repositório Comum, Lisboa, p.01-212, 22 set. 2012. Semanal. 